\title{
¿El mercado matrimonial en desbalance? El caso de México en 1980*
}

\author{
Norma Patricia Pavón**
}

En un mercado matrimonial, como en cualquier tipo de mercado, uno de los elementos importantes que determina el número de transacciones (uniones) que se llevan a cabo al interior del mismo, es el grado de equilibrio existente entre el número de oferentes y demandantes de un producto determinado, que en este caso particular y complejo es un producto sociocultural específico: los mismos oferentes y demandantes, es decir, la población de ambos sexos en edad casadera (soltera, entre los 12 y los 50 años) expuesta al riesgo de unirse.

El objetivo de este trabajo es presentar los resultados obtenidos al estimar qué tan balanceada, numéricamente, se encontraba la población casadera mexicana de 1980, en función de su estructura por edad y sexo, así como del calendario de su nupcialidad. Esta estimación se realizó tanto a nivel nacional como estatal, utilizando como fuente de información al Censo de 1980, corregido por subenumeración y mala declaración de la edad. Para realizarla se construyeron dos indicadores: la relación de femineidad por edad individual y la relación de femineidad por grupo de edad. Ambas son similares al conocido índice de masculinidad, con la diferencia de que, por un lado, relacionan a hombres y mujeres casaderos entre los que media una cierta diferencia de edades, de acuerdo con las tendencias previas a 1980, observadas en la población mexicana al momento de unirse por primera vez; por otro lado, hacen referencia a la edad o grupo de edad de las mujeres y no a la de los hombres.

A través de los resultados obtenidos se observa que es posible agrupar a 28 de las 32 entidades federativas del país en 6 diferentes pautas en cuanto al comportamiento de su relación de femineidad por edad individual. De éstas, sólo una muestra un mayor número de hombres que de mujeres en la población soltera mayor de 23 años, la que agrupa a las entidades de Hidalgo, Baja California Sur, Nayarit, Quintana Roo, Sinaloa y Sonora. En las cinco pautas restantes, en las cuatro entidades calificadas

* El presente artículo es una síntesis de la investigación realizada en la tesis "El desequilibrio entre los sexos en la población casadera: México 1980", presentada por la autora ante El Colegio de México para optar al Grado de Maestra en Demografía en febrero de 1990; la cual fue asesorada, en su carácter de Directora de Tesis, por la profesora Julieta Quilodrán de Aguirre, a quien, la que aquí suscribe, desea patentizar su profundo agradecimiento por los valiosos consejos y comentarios recibidos.

** Investigadora del Centro de Estudios Demográficos y de Desarrollo Urbano de El Colegio de México. 
como "atípicas", así como a nivel nacional, también se observa un marcado desbalance, sólo que éste se presenta en forma de déficits de hombres (o superávit de mujeres). Estos resultados son corroborados por las relaciones de femineidad por grupo de edad. En general, puede decirse que la región centro norte del país es la más afectada por este fenómeno. ya que las entidades con mayores desequilibrios al interior de sus respectivos mercados matrimoniales fueron Zacatecas, Guanajuato. Michoacán. Jalisco y Aguascalientes.

\section{Introducción}

Cuando se hace referencia al término "mercado" en una expresión, como es el caso del título de este artículo, debemos tener presente que dicho término tiene varias acepciones de acuerdo con la disciplina y forma en que se utilice.

Antiguamente, cuando se hablaba de un mercado, se aludía a un lugar espacialmente determinado donde se reunían compradores y vendedores a participar en un intercambio. Actualmente, el término es utilizado en formas diferentes además de la anterior.

Así, para los economistas, un mercado es un conjunto de compradores y vendedores; los empresarios, por su parte, usan el término coloquialmente, de tal forma que abarque agrupaciones variadas de consumidores, por lo que hablan de mercados de productos (i.e., mercado del calzado), mercados de necesidades (i.e. mercado de buscadores de dietas), mercados geográficos (i.e., mercado francés) y mercados demográficos (i.e., mercado juvenil), entre otros (Kotler, 1984).

Sin embargo, en general, se puede pensar que un mercado consiste en todos los consumidores potenciales que comparten una necesidad o deseo particular y que podrían y estarían dispuestos a participar en un intercambio que satisficiera esa necesidad o deseo. Por tanto, el tamaño del mercado depende del número de personas que muestran una necesidad particular, tienen los recursos que interesarian a otros y están dispuestos a ofrecer estos recursos en intercambio por lo que ellos quieren.

Para que dicho intercambio se pueda llevar a cabo se deben satisfacer ciertas condiciones: 1) que existan dos partes interesadas en establecer un intercambio; 2) que cada una de las partes tenga algo que pueda ser de valor para la otra; 3) que ambas partes sean capaces de comunicarse y surtir su producto; 4) que ambas partes sean libres de aceptar o rechazar la oferta, y 5) que cada parte considere apropiado o deseable negociar con la otra parte (Kotler, 1984). 
Con respecto a la primera condición, ¿qué sucede cuando en un mercado el número de oferentes es mayor que el de demandantes, o viceversa? Hablamos entonces de que el mercado se encuentra desbalanceado. El número de transacciones que podrían llevarse a cabo al interior del mercado se vería limitado no sólo por existir dicho desbalance, que por sí solo ocasionaría que un cierto número de integrantes de la parte más numerosa no estuviesen en posibilidades de realizar un intercambio, sino también porque, aun cuando aquellos que sean menos numerosos pudiesen encontrar, numéricamente hablando, suficientes miembros de la otra parte con los cuales intentar un intercambio, faltaría por cumplirse el resto de las condiciones, de tal forma que dicho intercambio pudiese llevarse a cabo satisfactoriamente.

Específicamente con respecto al mercado matrimonial, éste tiene características especiales, ya que se encuentra conformado por toda la población en edad casadera que potencialmente está expuesta al riesgo de unirse. En otras palabras, el mercado matrimonial estaría constituido por dos partes, la población masculina y la población femenina (como oferentes y demandantes de un producto sociocultural específico, ellos mismos), de una cierta edad (cuyo rango definiremos más adelante), expuestos al riesgo de unirse. En el entendimiento de que con dicha unión lograrían satisfacer las necesidades y deseos de ambas partes.

En las transacciones (uniones) que pudiesen tener lugar al interior del mercado matrimonial intervienen muchos y muy diversos factores. Para que se produzca una unión, es necesario que exista un hombre y una mujer que ofrezcan, y a la vez adviertan en su posible pareja, una serie de características apropiadas y deseables para ambos (edad, raza, educación, estrato socioeconómi(co, etc.). Ahora bien, ¿qué o quién determina las características consideradas como "apropiadas" o "deseables" para o de un determinado individuo? ¿Es una decisión personal o está influida por la sociedad o algún medio social y/o económico al que pertenece la posible pareja? Cuando hablamos de que en el mercado matrimonial interviene toda la población masculina y femenina en edad casadera, ¿nos referimos a la población mundial, de cada país, de una sociedad determinada o de un conjunto poblacional específico? En otras palabras ¿nos referimos sólo a círculos matrimoniales (Henry, 1969a y 1969b) específicos al interior de los cuales se forman las parejas (uniones endógamas)? La respuesta a todas estas interrogantes, y a muchas más que se nos quedan en el tintero, dista mucho de ser fácil. El objetivo de plantearlas sólo es el de poner de manifiesto la enorme complejidad que encierra el estudio del mercado matrimonial. De hecho, por lo general, ésta 
es una labor que ha recaído en los hombros de los sociólogos, quienes han intentado aproximarse a estos aspectos de la nupcialidad a través del análisis del proceso de selección del cónyuge (Girard, 1964; Glick, Heer y Beresford, 1963; entre otros).

Sin embargo, advertimos que una determinada población en edad casadera, al elegir a su posible pareja, no sólo se enfrenta a las presiones derivadas de las regulaciones socioculturales y económicas ejercidas por la sociedad de la que forma parte, sino que también se enfrenta a la presión derivada de la evolución de los factores demográficos de los cuales dependen características tales como su número y su estructura por edad y sexo.

Al tratar de estudiar la forma en que los factores demográficos pudiesen haber intervenido en el proceso de formación de las parejas, apreciamos que la mayoría de los estudiosos del tema han enfocado sus esfuerzos al análisis de variables tales como las proporciones de unidos y la edad a la primera unión, intentando estimar a través de éstas la intensidad y calendario de la nupcialidad. Sin embargo, son pocas las investigaciones demográficas que han profundizado sobre lo que hay detrás de las diferentes edades a la primera unión que se observan en los distintos países del mundo, así como del número de uniones que se realizan en ellos. Entre los trabajos de investigación que sí han abordado el tema desde esta perspectiva, se hace patente el esfuerzo llevado a cabo por ahondar en la complejidad inherente a la interacción humana, especialmente cuando ésta tiene como finalidad la selección del cónyuge y la formación de la familia. Algunas de estas investigaciones intentaron establecer un marco sociológico que manifestara la importancia de las variables que median entre la estructura social y los patrones matrimoniales observados, variables que incluyen tanto la factibilidad, social y económica, de contraer una unión, como qué tan deseable es dicha unión a nivel social e individual y qué tan disponibles se encuentran los efectivos de la población casadera de un sexo con respecto al otro (Dixon, 1971). Otros estudios buscaron incorporar, tanto el círculo o grupo disponible expuesto al riesgo de contraer una unión (Henry, 1969a y 1969b), como la competencia existente al interior de ese grupo y a los patrones de selección normativos de raza, edad y educación (Goldman et al., 1984). Sin embargo, la mayor parte de los estudios enfocaron sus esfuerzos primordialmente a la estimación del grado de desbalance entre los efectivos en presencia de uno y otro sexos en la población en edades casaderas (Goldberg, 1965; Henry, 1966; Akers, 1967; Hirschman y Matras, 1971). Para ello, se abocaron a la construcción de aquellos indicadores que, en opinión de cada autor, podrían proporcionar una buena estimación del des- 
equilibrio entre los sexos. Cabe hacer notar que a este desequilibrio se le conoce como marriage squeeze (presión matrimonial), ya que así fue como Glick, Heer y Baresford (1963), denominaron al dilema enfrentado por las mujeres que alcanzan la edad casadera en situación desventajosa por encontrarse en sobrenúmero en relación con los hombres con los que podrían contraer matrimonio.

Ahora bien, es un hecho conocido que, en una población no sujeta a "perturbaciones" demográficas tales como fuertes migraciones, altas tasas de mortalidad, etc., su índice de masculinidad, esto es, el número de hombres por cada 100 mujeres, debe mostrar una serie de regularidades en su comportamiento por edad, a partir de las cuales es posible inferir que existen altas probabilidades de que la mayor parte de la población encuentre pareja, es decir, que exista el llamado "matrimonio universal".

No obstante, es indudable que las poblaciones en el mundo se ven sujetas, en mayor o menor grado y en un tiempo o en otro, a variaciones en su perfil demográfico, derivadas éstas, por ejemplo, de guerras, epidemias, migraciones por razones políticas o económicas e, incluso, fuertes incrementos en sus tasas de natalidad o fuertes decrementos en las de mortalidad como resultado de los avances tecnológicos en el área de salud, propios o importados de otras naciones. Todo lo cual se ve reflejado en la estructura y composición por edad y sexo de una población en un momento dado, y es a través de los efectivos en presencia de uno y otro sexos que la dinámica demográfica de una población hace sentir su efecto sobre la nupcialidad. Esto equivale a afirmar que el número y edad de la población al unirse depende no sólo de la selectividad sociocultural, sino también del número y edad de los efectivos que forman parte de su población en "edad casadera".

Por tanto, que los efectivos casaderos se encuentren balanceados, al menos en términos númericos, es un factor determinante para que exista el llamado matrimonio universal en una población, es decir, para que, al interior de un mercado matrimonial, las partes involucradas, hombres y mujeres, encuentren suficientes miembros del sexo opuesto para elegir, de acuerdo a toda la gama de factores socioculturales, a su compañero(a) "apropiado(a)" y "deseable". Debido a la importancia del "factor equilibrio", surgen entonces otro tipo de interrogantes en cuanto al estudio de caso que pretendemos realizar: ¿qué tan equilibrados se encuentran los efectivos de ambos sexos que conformaban la población casadera mexicana en 1980 ? ¿Cómo podemos estimar el estatus de equilibrio de dicha población? ¿Qué fuente de información sería conveniente utilizar para estudiar este fenómeno en el 
territorio mexicano? Éstas son precisamente el tipo de preguntas a las que se pretende dar respuesta en este trabajo. En otras palabras, el objetivo de este artículo es el de presentar los resultados obtenidos al estimar el grado de desbalance numérico en la población casadera mexicana de 1980 , en función de su estructura por edad y sexo, así como del calendario de su nupcialidad.

\section{Fuente de información}

La estimación de la situación de equilibrio de la población casadera en el territorio mexicano será realizada en dos niveles de análisis, a nivel nacional y a nivel entidad federativa, ya que se creyó importante, por un lado, conocer el grado de desbalance de la población casadera mexicana en su totalidad y, por otro, conocerlo a un nivel más desagregado que permitiera establecer el grado de uniformidad existente en el país o, por el contrario, los diferenciales al interior del mismo.

Para lograr el nivel de desagregación deseado, en una primera instancia se pensó en recurrir a la información obtenida a partir del Censo General de Población y Vivienda levantado en México en 1980. Desafortunadamente, dicha información adolece de serias deficiencias, especialmente en términos de omisión de efectivos de uno u otro sexo y de mala declaración de la edad (Gómez de León y Partida, 1986), las cuales repercutirían en gran medida en la estimación de la existencia y magnitud del desbalance entre los sexos en la población, ya que si éstos están subestimados y el grado de subestimación es diferente entre ellos, las estimaciones de su balance o desbalance se verían sesgadas. Asimismo, una mala declaración de la edad afectaría la estimación en la medida en que dicha deficiencia modificara a los efectivos de la población casadera en general a cada edad y de los diversos grupos de edad utilizados en la construcción de indicadores en particular.

Para evitar los sesgos que podrían ocasionar las deficiencias de la información censal, se recurrió a las correcciones realizadas al Censo por Gómez de León y Partida (1986) a nivel nacional y a las elaboradas por Conapo-INEGI (1985) a nivel estatal.

Sin embargo, en términos de la información necesaria para llevar a cabo el objetivo de este trabajo, todavía hubo que enfrentar el problema que representaba no conocer, tanto a nivel nacional como estatal, a la población corregida por sexo, edad individual y estado civil. Lo cual, por un lado, planteó la necesidad de suponer que el porcentaje de población soltera dentro de la población corregida era el mismo que dentro de la población censada 
original, es decir, que las deficiencias censales no habian sido diferenciales por estado civil, puesto que, sin embargo, parece tener bases sólidas, ya que en la evaluación de la calidad y cobertura de la información censal sobre estado civil, éstas han sido señaladas como bastante correctas (Quilodrán, 1986); por otro lado, aun habiendo establecido los montos respectivos de población soltera, nacional y estatales, restaba el problema de que éstos estuviesen agregados en grupos quinquenales de edad. Para efectuar la desagregación a edades individuales, para ambos sexos, se utilizó el método conocido como Interpolante Cúbico de Trazador (Burden, R.L. y Faires, J.D., 1985), mismo que también permite la suavización de los llamados "apilamientos" poblacionales derivados de la preferencia por los dígitos cero y cinco en la declaración de la edad de la población.

\section{Definición de conceptos y metodología}

Es importante resaltar que el universo de estudio de este trabajo dejó de ser llamado "mercado matrimonial", para recibir ahora el nombre de "población en edad casadera", buscando con ello evidenciar que no se pretende ahondar en las complejidades de dicho mercado, derivadas de los factores socioculturales que lo pudiesen regular, sino enfocar el análisis a la influencia que los factores demográficos pudiesen estar ejerciendo en él. Ahora bien, en términos generales, población casadera ha sido definida como el conjunto de efectivos en presencia de ambos sexos expuestos al riesgo de unirse. Antes de seguir adelante, es importante precisar qué es exactamente lo que entenderemos por dicho concepto a lo largo de este trabajo.

Las edades consideradas como "casaderas" serán aquellas comprendidas entre los 12 y los 50 años, ya que a través de las pautas observadas no sólo en México sino a nivel mundial se ha detectado que las primeras uniones contraídas antes de los 12 o después de los 50 años son muy escasas, tanto que se ha hecho costumbre entre los estudiosos del tema considerarlas nulas (Quilodrán, 1980).

Por otra parte, se considerarán como integrantes de la población casadera sólo aquellos efectivos de ambos sexos clasificados como solteros en el censo, esto es, quienes nunca han contraído una unión. La razón de esto se encuentra en que el comportamiento de una población respecto a la edad en que contrae una primera unión y el rango de edades dentro del cual estará su compañero(a) difiere sustancialmente del comportamiento de aquella parte de la 
población que ya ha experimentado una primera unión y se en cuentra nuevamente formando parte de la población casadera.

La diferencia primordial entre ambos conjuntos poblacionales, los solteros (nunca unidos) y los alguna vez unidos, lógicamente se encuentra relacionada con la edad, ya que el rango de edades de los segundos no sólo variará mucho dependiendo del número de años pasados en su primera unión y el lapso transcurrido entre la separación y una segunda unión sino que, además, el rango de edades entre las cuales estas personas seleccionarán a un nuevo compañero(a) es mucho más amplio que para los primeros. Otra diferencia no menos importante radica en los diferentes contextos socioculturales y de presión "social" en que se desenvuelven quienes no han contraído nunca una unión versus quienes ya lo han hecho y esa unión terminó en separación. Así, las diferencias existentes tanto en la amplitud de los rangos de edades como en las edades en sí en las cuales se seleccionará a la pareja, introducirían serios sesgos al tratar de estimar el desequilibrio entre los sexos si se considerara a ambos conjuntos dentro del universo poblacional por estudiar ya que, mientras que es hasta cierto punto más simple determinar aquellas edades en las cuales una determinada población contrae una primera unión, debido a las "regularidades" que se observan a través de los resultados de las diversas investigaciones al respecto en el mundo en general (ej., Coale, A., 1971), la determinación de la edad para una segunda o tercera unión es mucho más compleja, no sólo depende del momento en que se entra a formar parte nuevamente de la población casadera, esto es, al disolverse la primera unión, sino que también depende de una serie de factores económicos, socioculturales e incluso psicológicos de las diversas poblaciones o subpoblaciones que influirán tanto en la decisión de contraer nuevas nupcias como en la decisión de cuál es la edad más "conveniente" que deberá tener la pareja y cuál es la pareja más "adecuada" para ello.

Finalmente, habiendo planteado ya las edades y el estado civil que caracterizarán a una persona "casadera", faltaría establecer quiénes de entre ambas poblaciones, la masculina y la femenina, están expuestos al riesgo de unirse. Para ello habría que considerar la edad o el rango de edades en las que un hombre o una mujer solteros de determinada edad, entre los 12 y los 50 años, buscaría a su pareja.

La mayoría de los autores que han realizado investigaciones sobre la edad media a la primera unión coinciden en señalar como algo común a casi todas las sociedades en el mundo el hecho de que existe una diferencia en dicha edad entre hombres y mujeres. Como ejemplo de estas investigaciones, en el análisis de algunos 
países de América Latina, África, Asia y Europa (Quilodrán, J., 1980) se observó que estas diferencias fluctúan entre un mínimo de 2.5 años en Francia y un máximo de 5.8 años en Marruecos, siendo siempre mayores los hombres. Si se parte de los diferenciales observados en México, se aprecia que éstos son similares a los observados en los países europeos, esto es, tres años de diferencia, aunque a edades más tempranas (de acuerdo con lo obtenido a través de la Encuesta Mexicana de Fecundidad, EMF, en 1976 la edad media era de 24.1 años en los hombres y 21.1 años en las mujeres), diferencia que está presente en el país incluso a nivel entidad federativa (Quilodrán, 1980). Si bien no es posible establecer con precisión, en función a lo anteriormente señalado, la edad o el rango de edades entre los cuales una mujer o un hombre escogerían a su pareja en una sociedad como la mexicana, sí es posible, a partir de las tendencias observadas en México en la edad media a la primera unión (a través de censos y encuestas anteriores a 1980), establecer como supuesto que, en 1980, tanto a nivel nacional como estatal, existió una diferencia promedio de tres años entre los hombres y las mujeres al momento de unirse por primera vez, siendo siempre mayor la edad de los hombres.

A través de este supuesto, es factible ahora intentar establecer la edad o edades en las que un hombre (mujer) buscaría a su pareja, es decir, su edad y la edad de su pareja de tal forma que pudieran ser considerados como expuestos al riesgo de unirse. Primero, se puede suponer esa diferencia de tres años ya no como promedio sino como constante y relacionar así a mujeres solteras de edad $i$ con hombres solteros de edad $i+3$. En una segunda instancia, se podría mantener hasta cierto punto la idea de esa diferencia de tres años entre el hombre y la mujer al unirse por primera vez, pero ampliando al mismo tiempo la gama de opciones de cada individuo o grupo de individuos. Para esto, se relacionaría a las mujeres solteras de un cierto rango de edades $(i, i+n)$ con hombres solteros también dentro de un rango de edades de igual amplitud pero desplazado en el tiempo tres años $(i+3, i+3+n)$.

De esta manera, es posible acotar la definición general del término "población casadera" de tal forma que incluyese a toda aquella población soltera entre los 12 y los 50 años, salvo que ésta estará constituida a cada edad (i) o rango de edades $(i, i+x)$ por mujeres de dicha edad o en dicho rango de edades y por hombres tres años mayores que dichas mujeres $(i+3)$ o en un rango de edades donde el menor de ellos sea tres años mayor que la menor de las mujeres $(i+3, i+3+n)$. 


\section{Indicadores utilizados}

A partir de la definición de población casadera expresada en el último párrafo de la sección anterior, se construyeron dos indicadores, la relación de femineidad por edad individual $[R F(i)]$ y la relación de femineidad por grupos de edad $[R F(i, i+n)]$, mismos cuya implementación se consideró factible en el marco de las limitaciones de la información disponible y mediante los cuales se buscó estimar qué tan balanceada se encontraba la población casadera en el México de 1980.

Estos indicadores no son sino una versión modificada del llamado Índice de Masculinidad ya que, al igual que éste, son razones de sexos, sólo que mientras que el índice de masculinidad relaciona a hombres y mujeres de una misma edad, las relaciones de femineidad, tal y como serán usadas en este trabajo, relacionarán a hombres de edad $(i+3)$ con mujeres de edad $(i)$, o a hombres en el grupo de edad $(i+3, i+3+n)$ con mujeres en el grupo de edad $(i, i+n)$.

De hecho, la única razón por la que el nombre de estos índices está asociado a las mujeres (femineidad) se debe a que la edad (i) a la que se hará referencia al estimarlos o utilizarlos corresponderá a la edad de las mujeres y no a la de los hombres.

Las relaciones de femineidad serán entonces estimadas de la siguiente forma:

1) $R$ de $F$ por Edad $=\underline{\text { (Núm. Hom. Solt. edad } i+3)}$

Individual. $R F$ (i) (Núm. Muj. Solt. edad i)

2) $R$ de $F$ por Gpo. = (Núm. Hom. Solt. en G. de edad $i+3+n$ ) de Edad.

$R F(i, i+n)$

(Núm. Muj. Solt. en G. de edad $i+n$ )

En relación con este segundo indicador, se estimó el mismo tomando en consideración cuatro rangos de edades diferentes, cuya amplitud varía desde aquel que considera prácticamente a toda la población en edades casaderas, hasta el que se restringe a aquellas edades en las que fluctúa, en México en general y en las entidades federativas en particular, la edad a la primera unión.

Así, expresados de mayor a menor amplitud, los rangos en los cuales se estimarán las relaciones de femineidad por grupos de edad son los siguientes:

a) Aquel que toma en cuenta a toda la población casadera, esto es, a todas las mujeres solteras entre los 12 y los 49 años cum- 
plidos, asociándolas por ende con todos los hombres solteros entre los 15 y 52 años cumplidos, $R F(12-49)=$ Hombres solteros (1552)/Mujeres solteras (12-49).

b) Aquel que relaciona a las mujeres entre los 17 y los 28 años cumplidos con hombres entre los 20 y 31 años cumplidos, $R F(17$ 28) $=$ Hombres solteros (20-31)/Mujeres solteras (17-28).

c) Aquel que relaciona a las mujeres entre los 17 y 26 años cumplidos con hombres entre los 20 y 29 años cumplidos, $R F(17$ 26) $=$ Hombres solteros (20-29)/Mujeres solteras (17-26).

d) Y finalmente, aquel que relaciona a las mujeres entre los 18 y 25 años cumplidos con hombres entre los 21 y 28 años cumplidos, $R F(18-25)=$ Hombres solteros (21-28)/ Mujeres solteras (18-25).

Tanto en las relaciones de femineidad por edad individual como en las relaciones de femineidad por grupo de edades, el denominador siempre estará constituido por 100 mujeres solteras de edad (i) o en el grupo de edad ( $i, i+n)$, mientras que el numerador variará dependiendo del número de hombres solteros de edad $(i+3)$ o en el grupo de edad $(i+3, i+3+n)$ presentes en el país o en la entidad que se esté analizando.

\section{Estimación del estatus de equilibrio en la población casadera nacional y estatal}

A partir de la estimación de las relaciones de femineidad por edad individual en cada una de las 32 entidades federativas (cuadro 1), se observa que es posible agrupar a 26 de ellas en seis diferentes pautas, de acuerdo con el comportamiento de $s u R F(i)$ a lo largo de todo el rango de edades considerado (gráficas 1 a 6); en las cuatro entidades federativas restantes, Aguascalientes, Distrito Federal, Nuevo León y Zacatecas, la $R F(i)$ de cada una de ellas muestra un comportamiento que difiere en forma notable no sólo del comportamiento del resto de las entidades federativas sino también entre sí (gráfica 7). Entre las seis pautas observadas, sólo una mostró un mayor número de hombres que de mujeres entre la población soltera mayor de 23 o 24 años, aquella que agrupa a las entidades de Hidalgo, Baja California Sur, Nayarit, Quintana Roo, Sinaloa y Sonora (gráfica 1). En las cinco pautas restantes, así como en las cuatro entidades que mostraron relaciones de femineidad con un perfil que puede ser calificado como atípico, el desequilibrio entre los efectivos de ambos sexos actúa en detrimento de las expectativas nupciales de la población femenina, en el sentido de mostrar déficits de hombres solteros; situación que 


\section{GRÁFICA 1}

Estados con perfil de $\mathbf{R F}(\mathrm{I})$ similar a la población soltera estimada, 1980: pauta 1

Hom. por 100 muj.

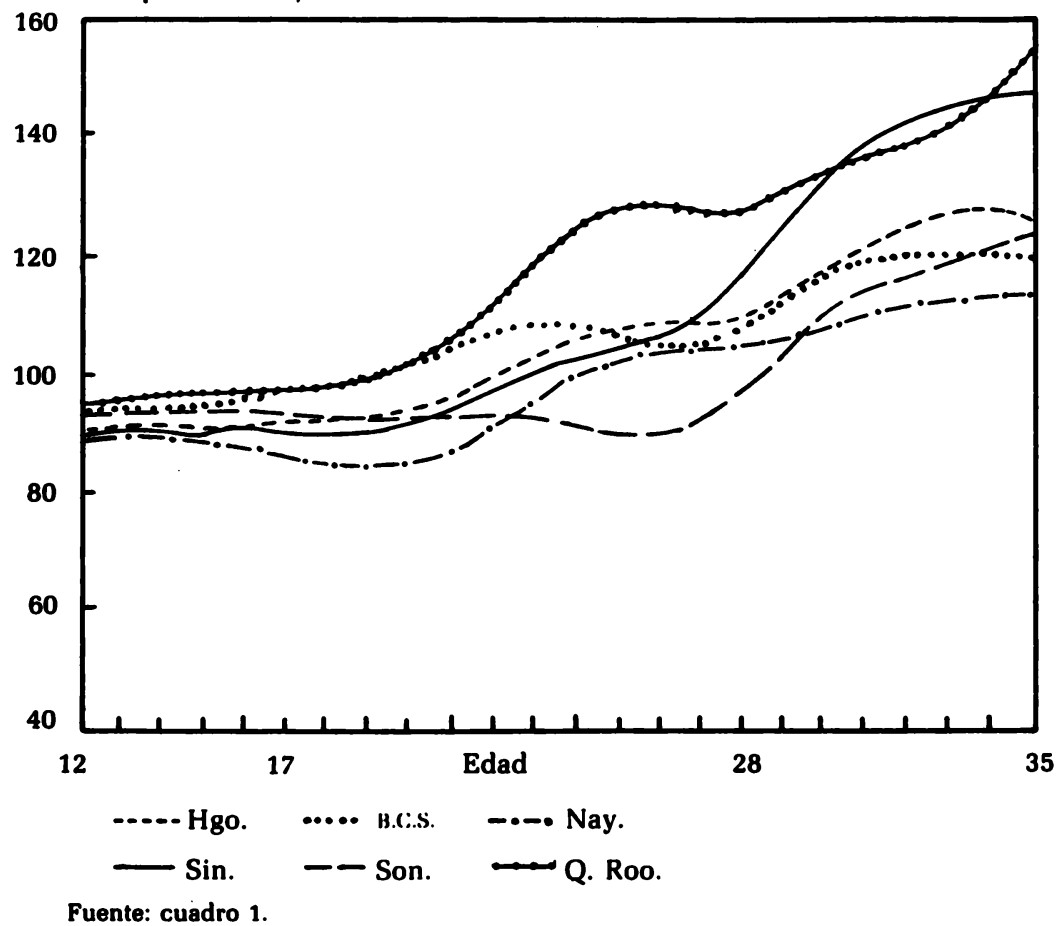

se observa especialmente problemática por la magnitud de dichos déficits tanto en la pauta que agrupa a las entidades de Jalisco, Guanajuato y Michoacán (gráfica 6) como en tres de las cuatro entidades "atípicas" ya mencionadas: Zacatecas, Aguascalientes y el Distrito Federal. Nótese que al momento de graficar el comportamiento de las relaciones de femineidad por edad individual, se mostraron éstas sólo para las edades entre los 12 y los 35 años; se creyó apropiado hacerlo así por dos motivos: primero, debido a que la incidencia de las primeras uniones después de los 35 años disminuye en forma notoria y segundo, debido al bajo volumen de población casadera después de esa edad; todo lo cual provoca que el comportamiento del indicador más allá de los 35 años se vuelva bastante irregular y poco confiable. 
GRÁFICA 2

Estados con perfil de RF(I) similar a la población soltera estimada, 1980: pauta 2

Hom. por 100 muj.

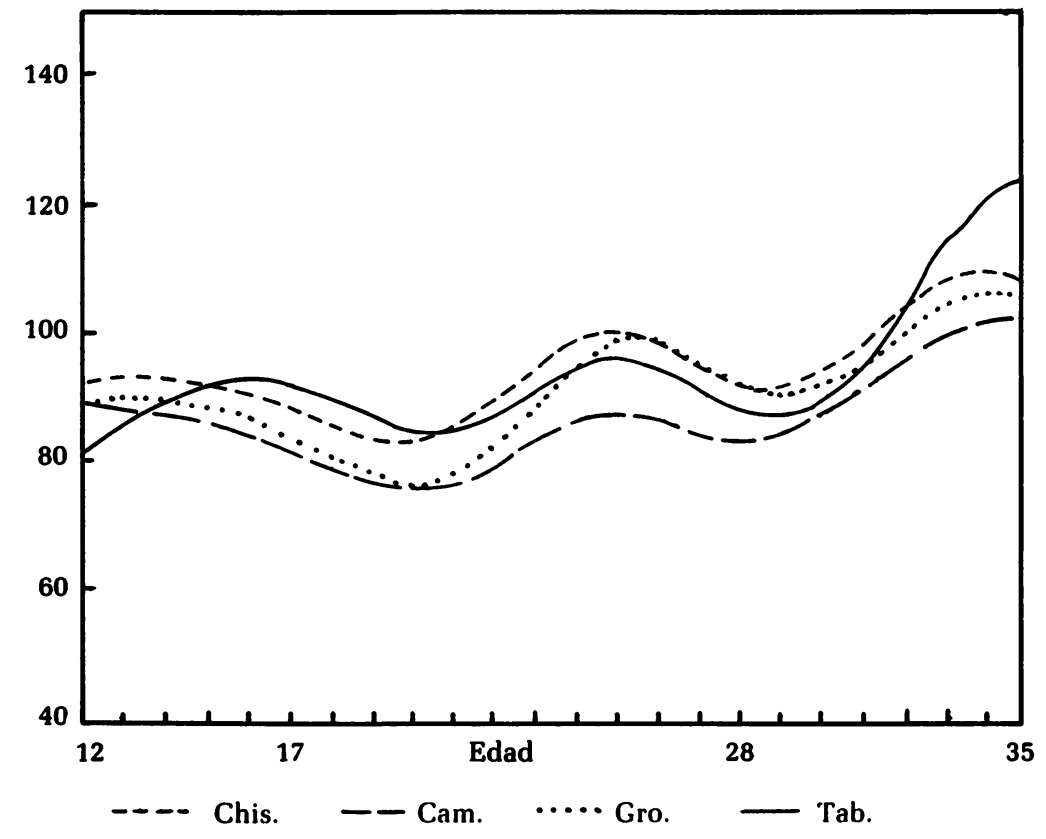

Fuente: cuadro 1.

En cuanto a los resultados obtenidos al estimar las relaciones de femineidad por grupo de edad (cuadro 2), éstos muestran que sólo en el caso de dos entidades, Baja California Sur y Quintana Roo, se produce un superávit de hombres, aunque éste nunca es muy elevado, ya que las $R F(i, i+n)$ son inferiores a 106/100, y sólo tres entidades parecen tender, hasta cierto punto, al equilibrio: Hidalgo, Sinaloa y Sonora, en donde las $R F(i, i+n)$ son superiores a 92/100 pero sin alcanzar los 100 hombres por cada 100 mujeres. En las 27 entidades restantes se advierte un déficit de hombres, destacando los casos de Zacatecas, Guanajuato, Aguascalientes, Michoacán, Jalisco y, en menor medida, Chihuahua, debido a que es en ellas en donde los déficits de hombres resultaron más importantes $R F(i, i+n)$, aproximadamente iguales a $66,72,72,72.3,75$ 
GRÁFICA 3

Estados con perfil de RF(I) similar a la población soltera estimada, 1980: pauta 3

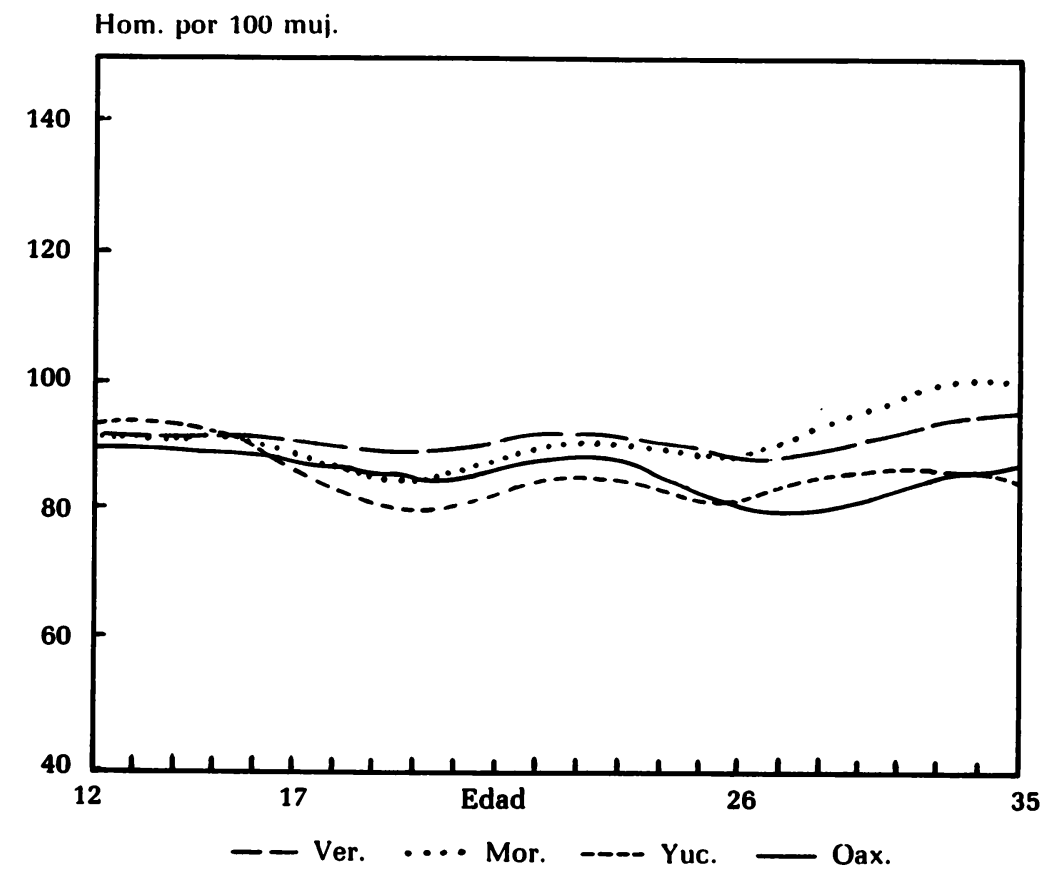

Fuente: cuadro 1.

y 79 hombres por cada 100 mujeres, respectivamente.

Comparando los resultados obtenidos a partir de la estimación de ambos tipos de relaciones de femineidad, se observó cierta consistencia en cuanto a las entidades que mostraron un mayor desbalance entre sus efectivos, ya sea que éste se produjese por un superávit de hombres o por un déficit de los mismos. Así, las entidades en las que el desbalance se produjo por un aparente superávit de hombres fueron Baja California Sur y Quintana Roo, mientras que las entidades en que, por el contrario, el desequilibrio se produjo por déficit importante de hombres fueron Zacatecas, Guanajuato, Michoacán, Jalisco y Aguascalientes. Por otro lado, la situación de los estados de Hidalgo, Sinaloa y Sonora es destacable por encontrarse en un punto intermedio en los resultados de 


\section{GRÁFICA 4}

Estados con perfil de RF(I) similar a la población soltera estimada, 1980: pauta 4

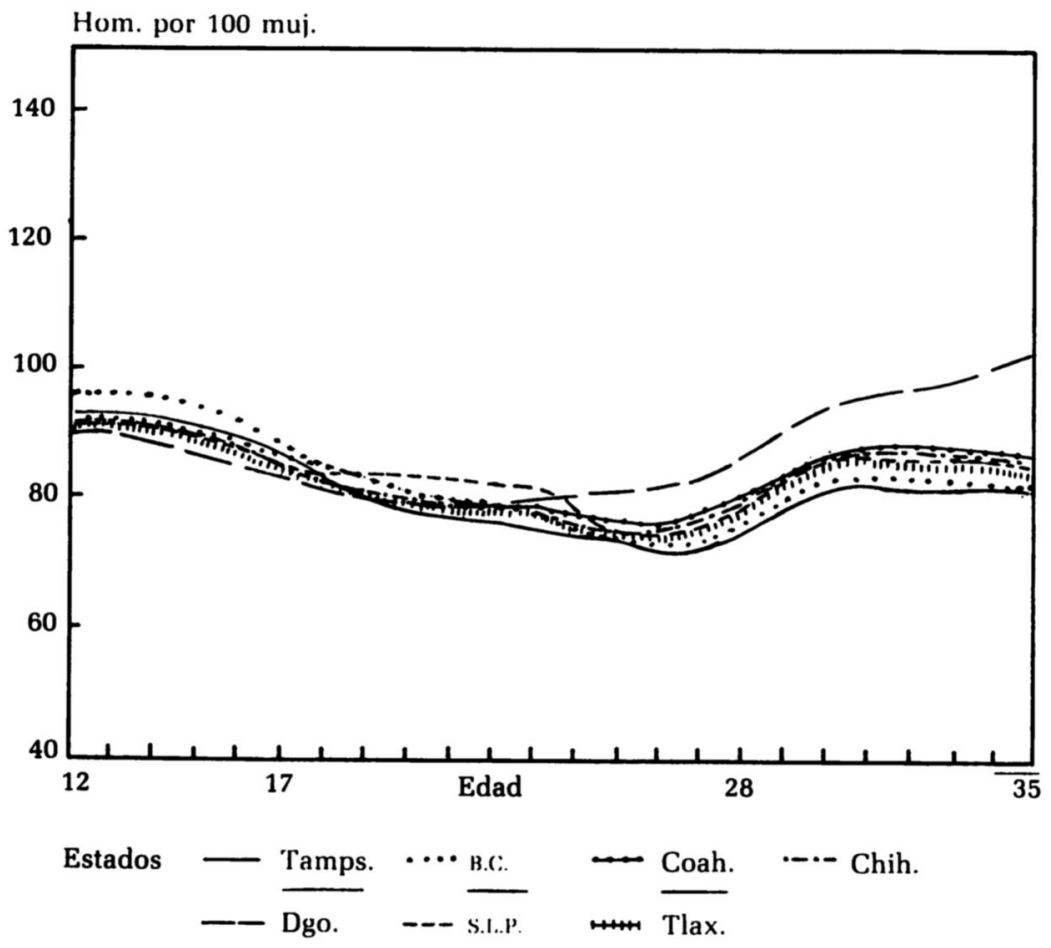

Fuente: cuadro 1.

ambos tipos de estimaciones, ya que, al estimar las relaciones de femineidad por edad individual mostraron tener superávit de hombres después de los 23 años y al estimar las relaciones de femineidad por grupo de edad se advierten en ellas ligeros déficits de hombres en todos los rangos de edades analizados. En todas las 22 entidades federativas restantes, así como a nivel nacional (gráfica 8 y cuadro 2), se observaron déficits claros de hombres pero sin alcanzar magnitudes demasiado relevantes. 


\section{GRÁFICA 5}

Estados con perfil de RF(I) similar a la población soltera estimada, 1980: pauta 5

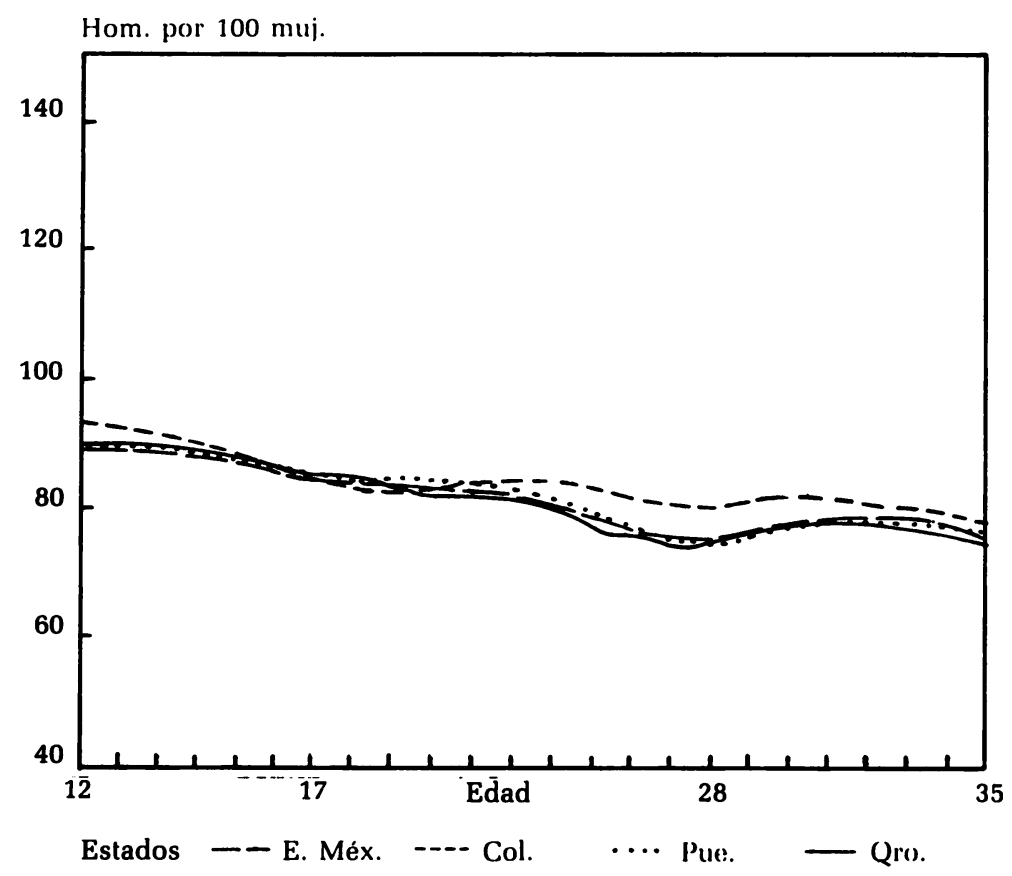

Fuente: cuadro 1.

\section{Conclusiones}

Si consideramos que el número de habitantes totales y solteros en Baja California Sur y Quintana Roo es relativamente pequeño, especialmente si se les compara con los volúmenes de estas poblaciones en las demás entidades del país, sería de esperarse que cualquier pequeño cambio en la magnitud y/o composición por edad y sexo de los mismos alterará las estimaciones de las relaciones de femineidad; por tanto, el abstraer alguna conclusión respecto al estatus de equilibrio de su población casadera sería bastante arriesgado, especialmente tomando en cuenta los supuestos que fue necesario establecer al estimar a la población soltera, tanto por grupo quinquenal como por edad individual en todas las en- 
GRÁFICA 6

Estados con perfil de RF(I) similar a la población soltera estimada, 1980: pauta 6

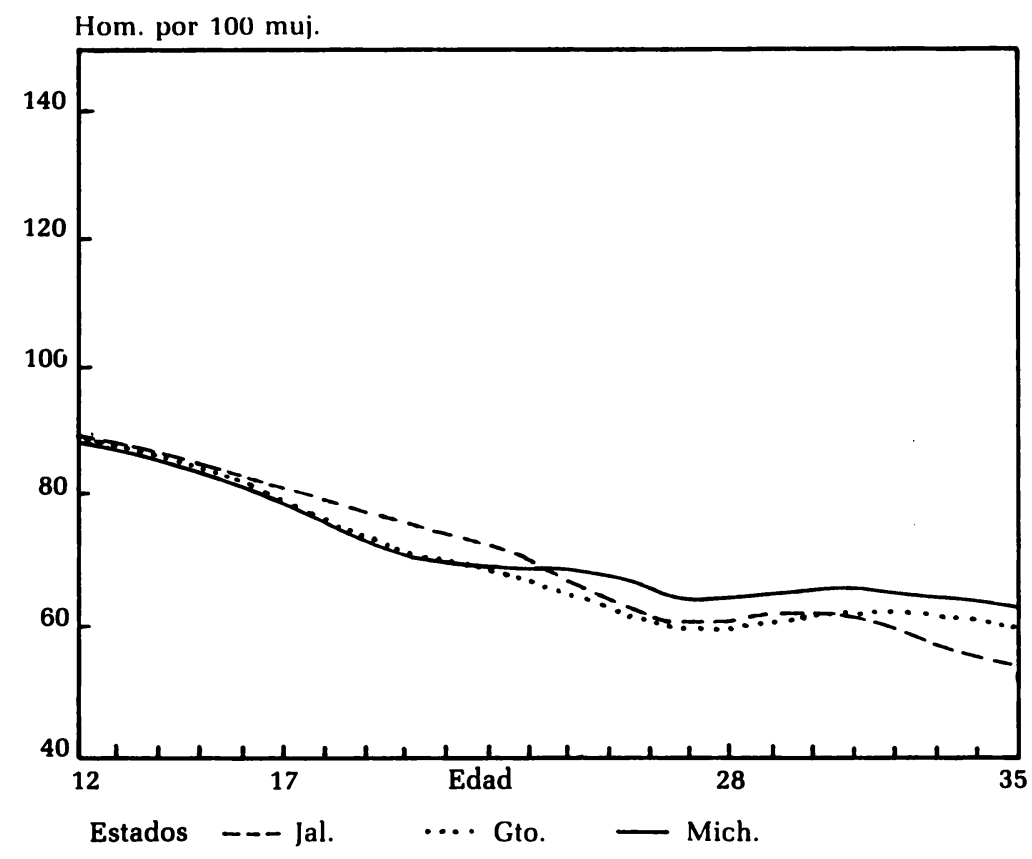

Fuente: cuadro 1.

tidades, y que, en su aplicación, introducen ciertos sesgos en las estimaciones de las relaciones de femineidad. No conocer la dirección y magnitud de estos sesgos, y que estas entidades en particular posean poca población, imposibilita poder afirmar en forma concluyente que la situación de la población casadera de ambas entidades, Baja California Sur y Quintana Roo, es tal que las convertiría en las únicas entidades federativas del país cuya población casadera o bien muestra claros superávits de hombres o, en el mejor de los casos, sus efectivos de ambos sexos se encuentran equilibrados.

Por lo que, excluyendo del universo de análisis a estas dos entidades, es posible advertir no sólo la presencia de un desequilibrio entre.los sexos en la población casadera mexicana de 1980 
GRÁFICA 7

Estados con perfil de RF(I) atípico, población soltera estimada, 1980

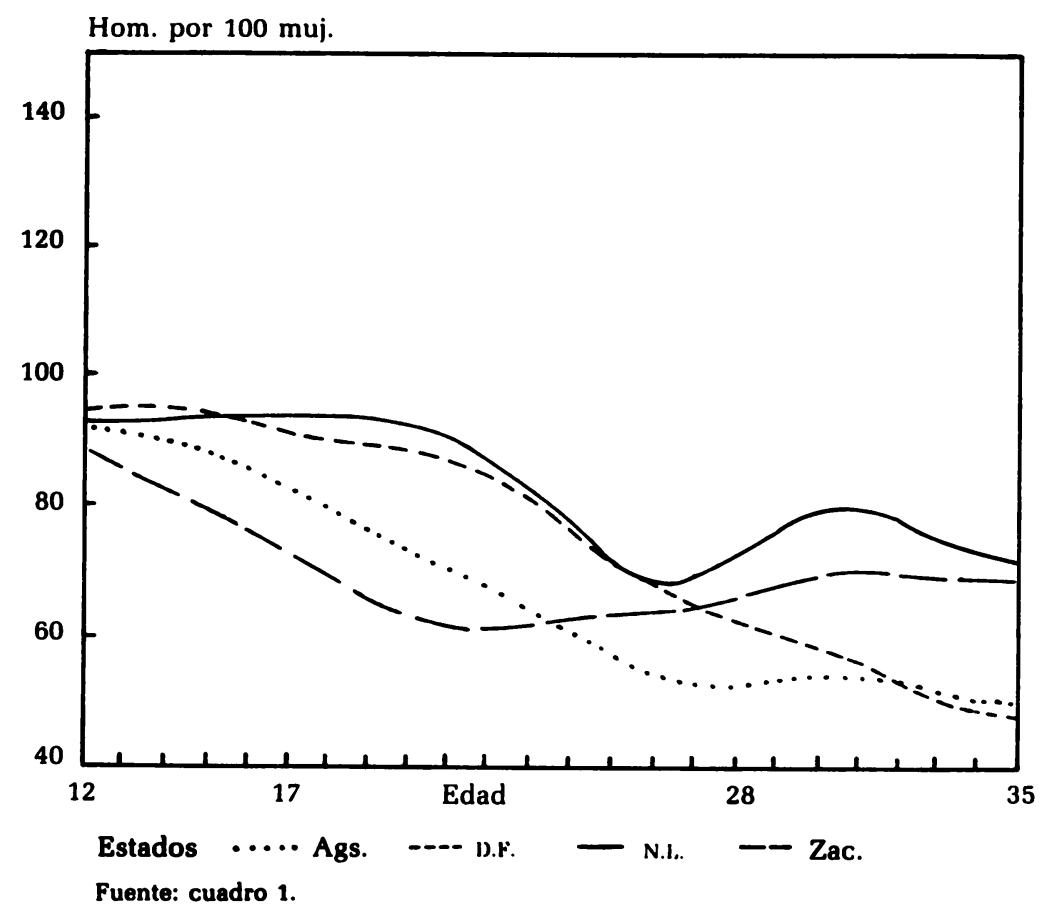

nacional y estatal, sino que el mismo se produce por un déficit importante de hombres solteros en la mayor parte de las edades consideradas como casaderas. Desde luego, otra forma de plantear esta conclusión y que podría ser una situación que se esté dando en algunas entidades, es que el desequilibrio no se hubiese producido por un déficit de hombres solteros sino por un superávit de mujeres solteras en edades casaderas.

Para dilucidar cuál de los dos planteamientos sería el más acertado, habría que adentrarse en los orígenes de estos desequilibrios mediante el análisis de los factores demográficos cuya particular evolución ha dado lugar a la estructura por sexo y edad de la población casadera mexicana de 1980 .

Sin embargo, cualquiera que sea la conclusión más acertada en cada entidad, es posible afirmar que los efectivos que conformaban a dicha población casadera se enfrentaron no sólo a la pre- 


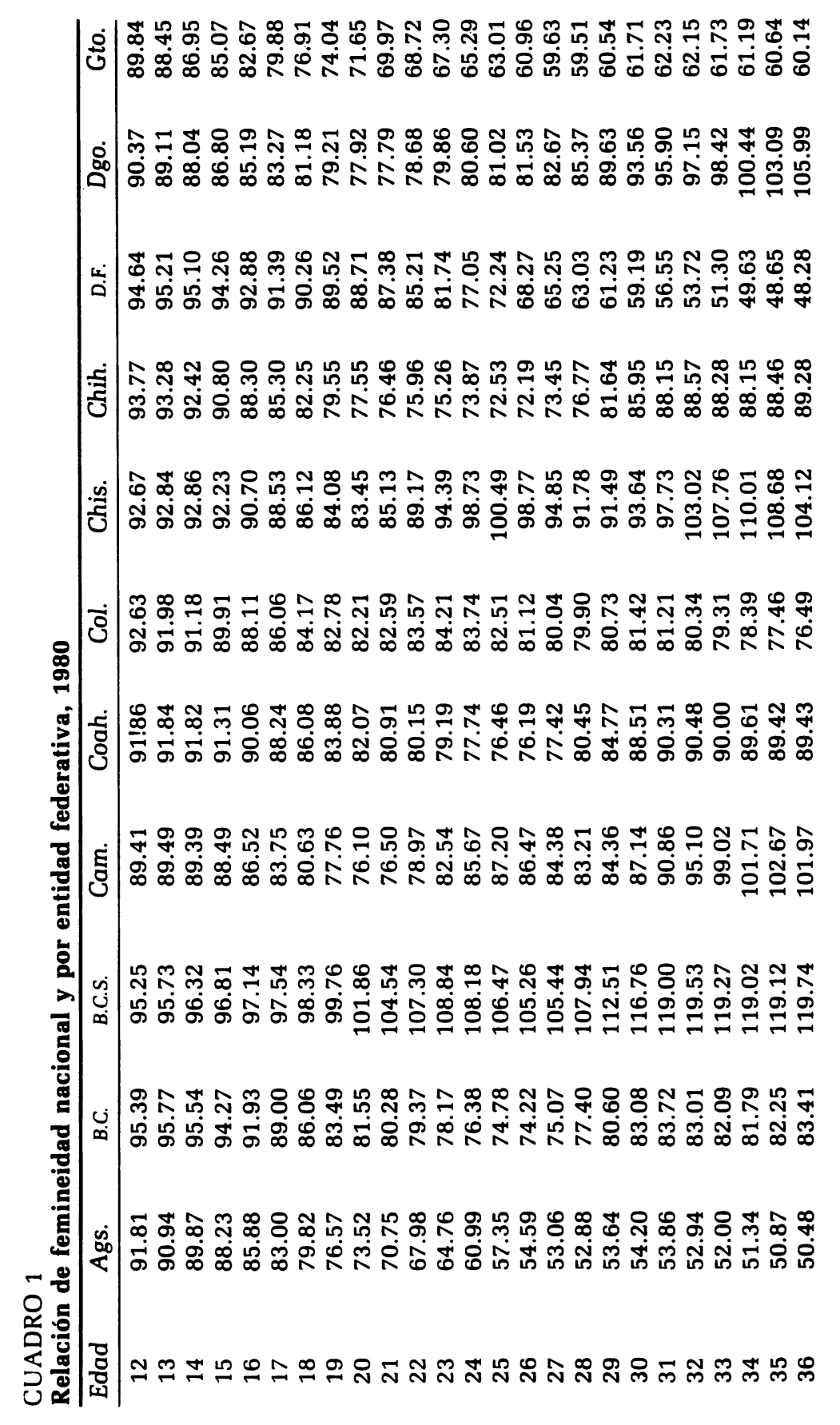




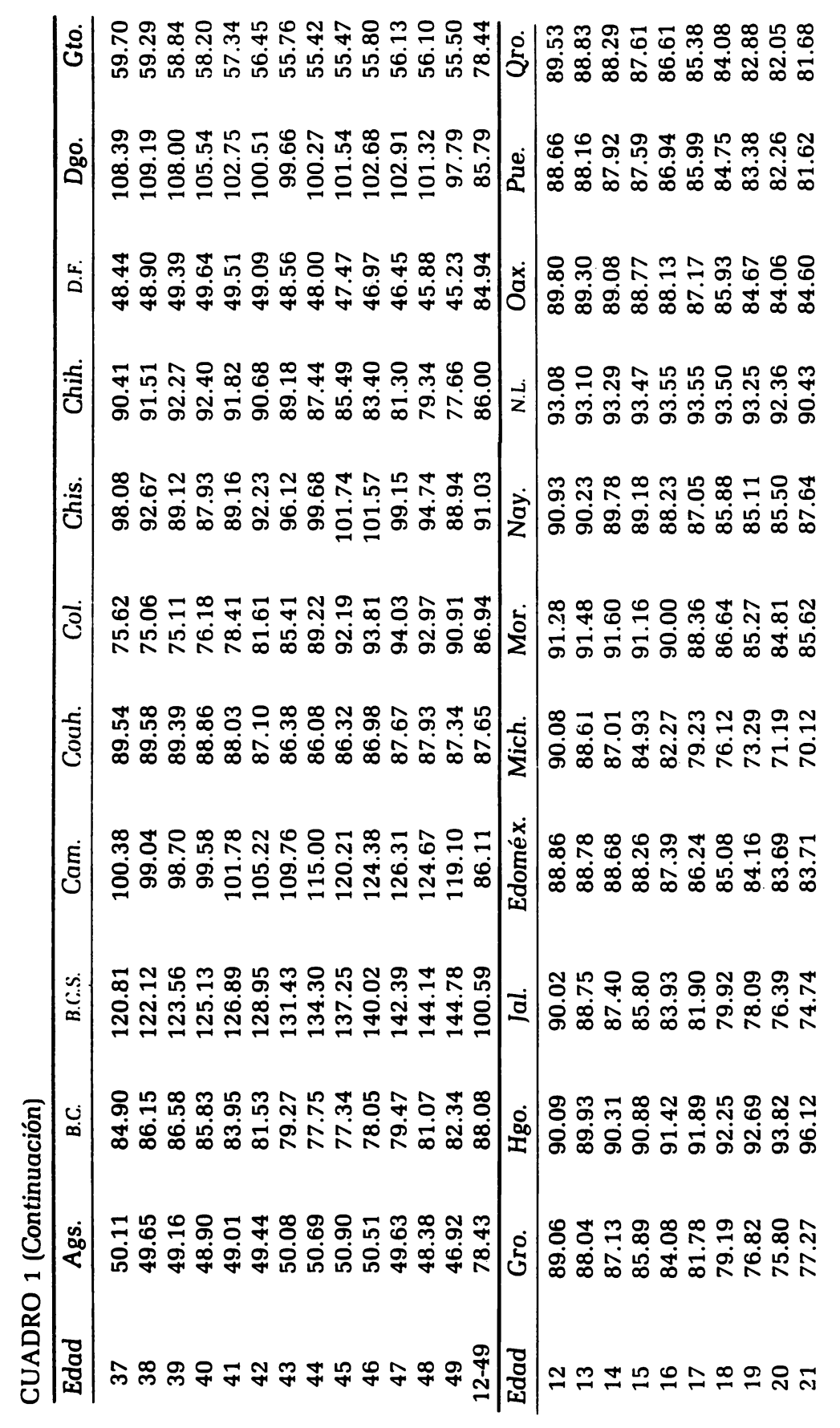




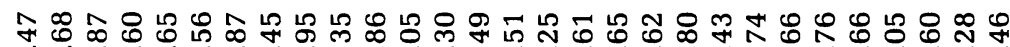

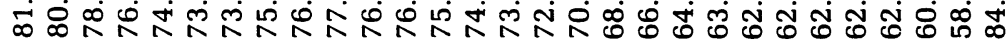

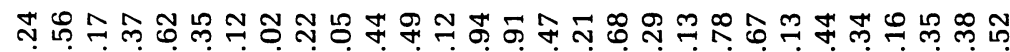

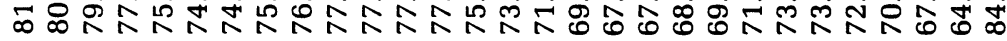

욱오ำ இ

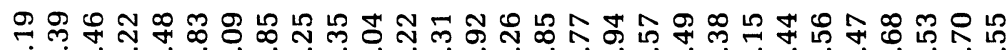

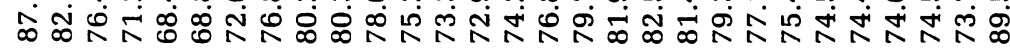

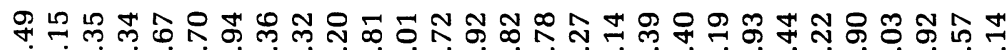

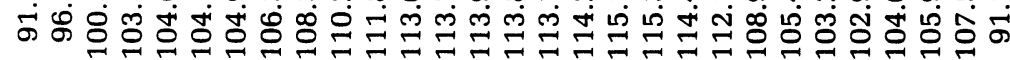

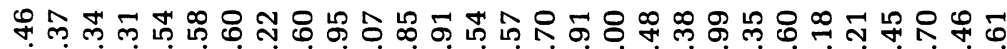

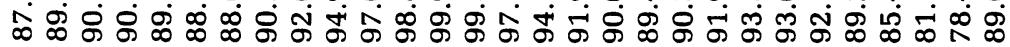

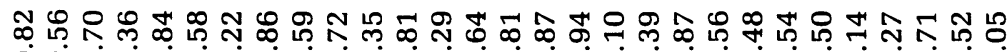

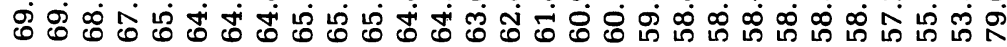

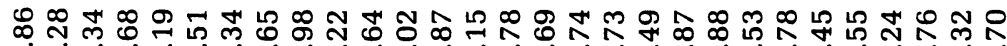

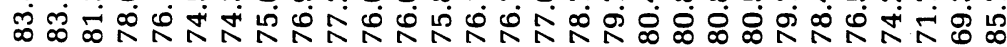

局 숫

ศิ

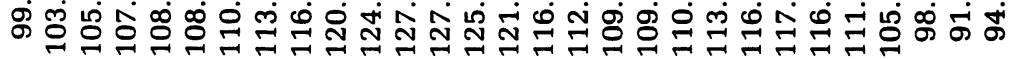

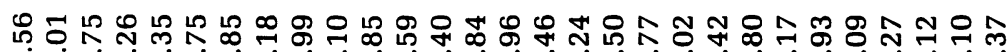

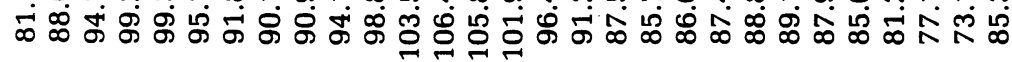

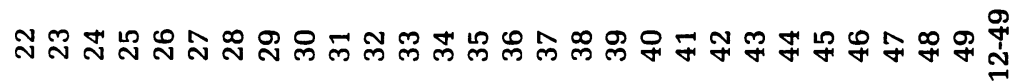




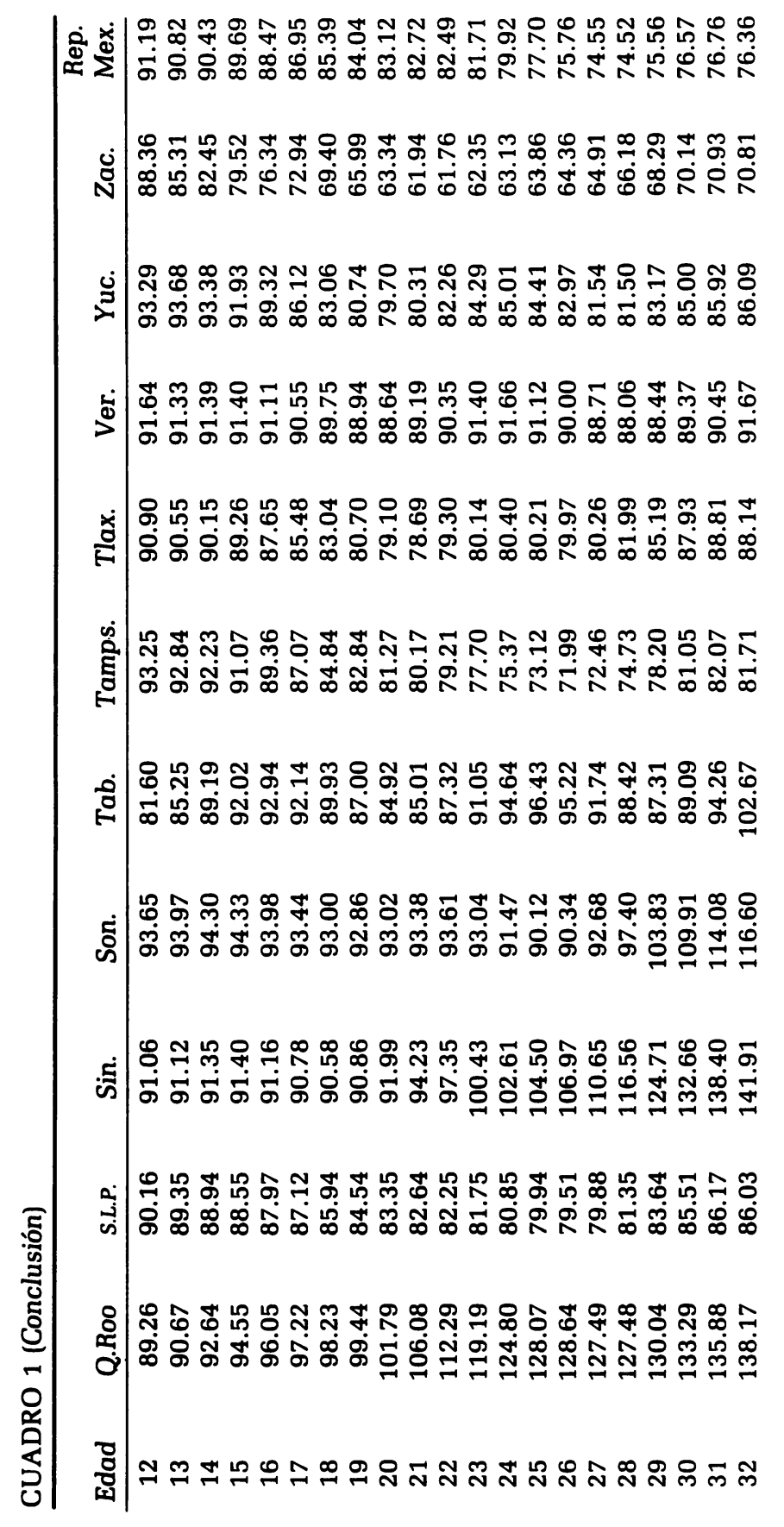




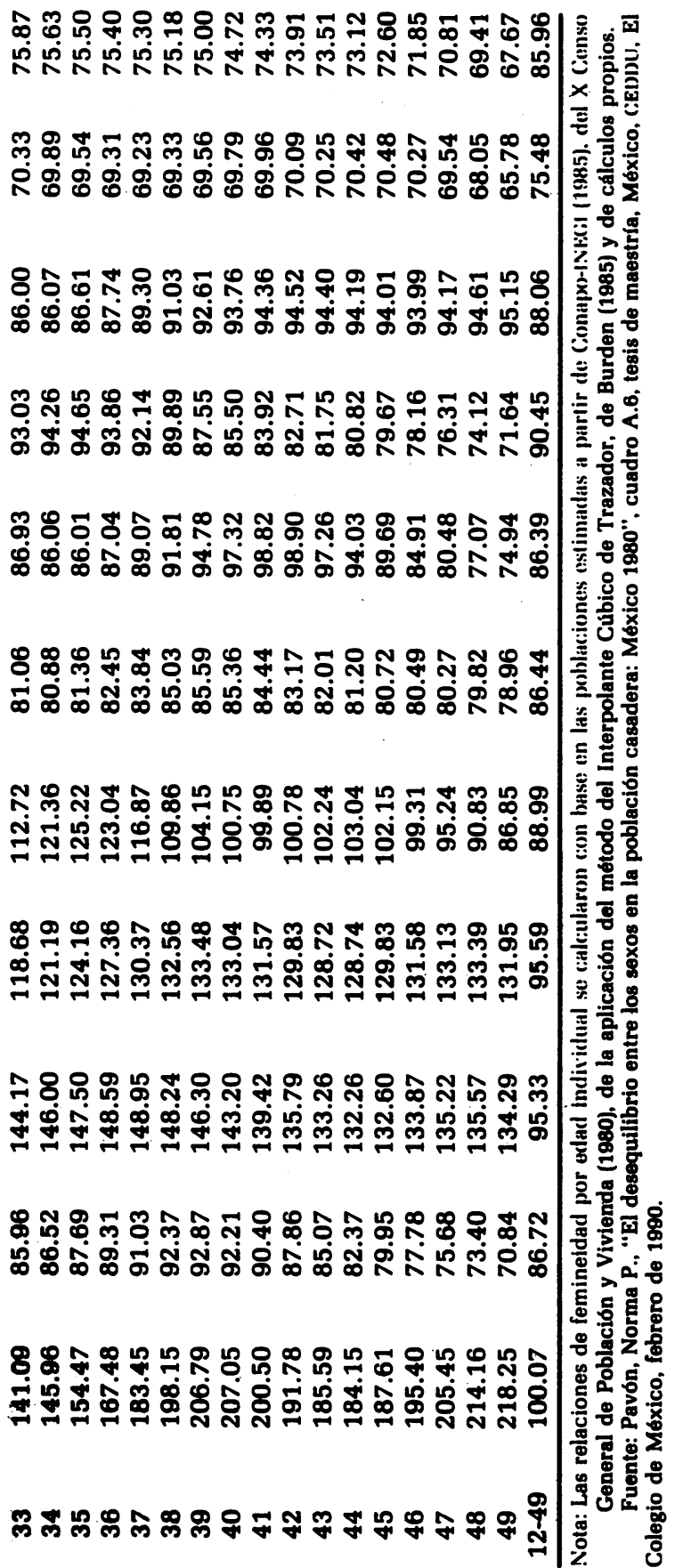


GRÁFICA 8

República mexicana: perfil de RF(I), población soltera estimada, 1980

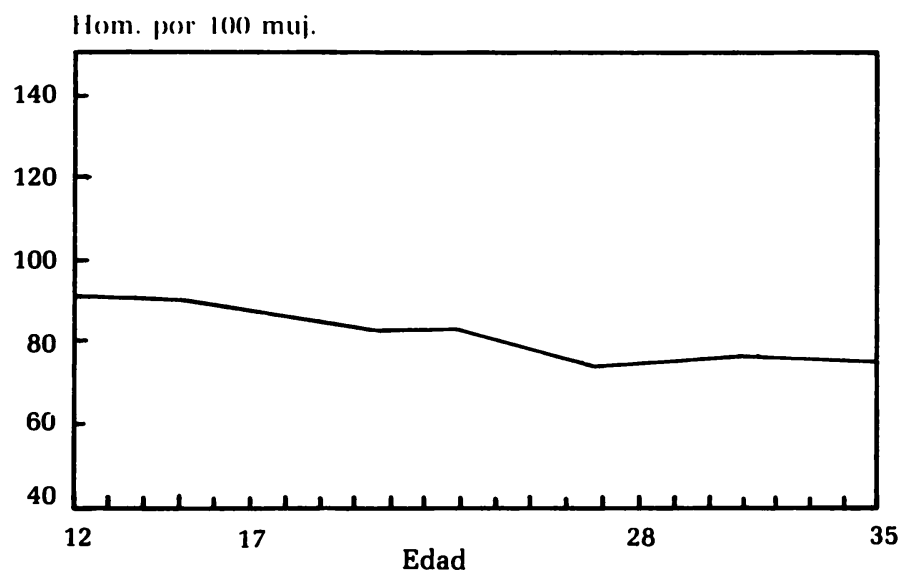

sión social derivada de la "concepción" de cuáles eran las edades apropiadas para contraer una unión y cuál la pareja más "conveniente" para hacerlo, sino también al hecho de ver disminuidas sus posibilidades de contraer al menos una unión, simplemente por encontrarse desequilibrados numéricamente. La estimación del nivel de este desequilibrio a cada edad y dentro de rangos de edades específicos demuestra la enorme magnitud de la llamada presión matrimonial (marriage squeeze).

Al observar la enormidad del desbalance entre los sexos en la población casadera mexicana de 1980 surge, inevitablemente, la inquietud por conocer qué fue lo que dio lugar a éste en términos demográficos, y cuál pudiese haber sido su efecto en la intensidad y calendario de la nupcialidad de dicha población. Por lo que antes de concluir este trabajo se realizó un análisis, a nivel exploratorio, de la dinámica deınográfica nacional, intentando desentranar los orígenes del fenómeno.

Ahora bien, si tomamos en cuenta que cuando una población crece aceleradamente, por esa sola razón, da lugar a que las generaciones más jóvenes vayan siendo más numerosas que aquellas que les precedieron, y si a ello añadimos el hecho de que en esta investigación, y en razón a las tendencias encontradas, se asociaron como parejas potenciales a los efectivos masculinos y femeninos de generaciones entre las que mediaba una cierta diferencia de años, es factible entonces vislumbrar cierta relación entre los 
CUADRO 2

Relaciones de femineidad por grupos de edad. Población soltera estimada, 1980

\begin{tabular}{|c|c|c|c|c|}
\hline \multirow[b]{2}{*}{ Entidad } & \multicolumn{4}{|c|}{ Grupos de edad } \\
\hline & $12-49$ & $17-28$ & $17-26$ & $18-25$ \\
\hline Zacatecas & 75.48 & 66.47 & 66.51 & 64.86 \\
\hline Guanajuato & 78.44 & 71.99 & 72.68 & 71.44 \\
\hline Michoacán & 79.05 & 72.70 & 73.12 & 71.90 \\
\hline Aguascalientes & 78.43 & 72.04 & 73.17 & 71.79 \\
\hline Jalisco & 79.08 & 74.79 & 75.60 & 74.85 \\
\hline Chihuahua & 86.00 & 79.01 & 79.20 & 77.98 \\
\hline Durango & 85.79 & 80.45 & 80.30 & 79.45 \\
\hline Campeche & 86.11 & 80.63 & 80.48 & 79.36 \\
\hline Guerrero & 85.37 & 81.67 & 81.18 & 80.39 \\
\hline Tlaxcala & 86.39 & 81.50 & 81.52 & 80.51 \\
\hline Tamaulipas & 86.44 & 81.27 & 81.67 & 80.81 \\
\hline Querétaro & 84.46 & 81.94 & 82.36 & 81.93 \\
\hline B.C. & 88.08 & 82.21 & 82.53 & 81.41 \\
\hline Puebla & 84.52 & 82.27 & 82.71 & 82.20 \\
\hline Yucatán & 88.06 & 82.72 & 82.78 & 81.91 \\
\hline Coahuila & 87.65 & 82.91 & 83.11 & 82.12 \\
\hline Rep. Mex. & 85.96 & 83.05 & 83.51 & 83.02 \\
\hline Colima & 86.94 & 83.50 & 83.69 & 83.22 \\
\hline Edo. de Méx. & 85.70 & 83.51 & 83.94 & 83.67 \\
\hline S.L.P. & 86.72 & 83.87 & 84.04 & 83.46 \\
\hline Distrito Federal & 84.94 & 84.50 & 85.91 & 85.82 \\
\hline Oaxaca & 86.89 & 85.70 & 85.93 & 85.63 \\
\hline Morelos & 89.61 & 87.16 & 87.09 & 86.67 \\
\hline Chiapas & 91.03 & 88.21 & 87.97 & 87.41 \\
\hline Nuevo León & 89.55 & 87.77 & 88.72 & 88.60 \\
\hline Nayarit & 91.14 & 89.77 & 89.06 & 88.98 \\
\hline Tabasco & 88.99 & 89.37 & 89.33 & 88.33 \\
\hline Veracruz & 90.45 & 89.84 & 89.92 & 89.76 \\
\hline Sonora & 95.59 & 92.95 & 92.86 & 92.83 \\
\hline Sinaloa & 95.33 & 94.65 & 93.85 & 94.16 \\
\hline Hidalgo & 94.44 & 96.33 & 95.71 & 96.24 \\
\hline B.C.S. & 100.59 & 102.06 & 101.83 & 102.77 \\
\hline Quintana Roo & 100.07 & 105.35 & 104.41 & 105.64 \\
\hline
\end{tabular}

desbalances encontrados y el crecimiento acelerado experimentado por la población mexicana en los años previos a 1980.

Para explorar qué tan cercana fue la relación entre el crecimiento acelerado de la población mexicana y el desbalance entre su población casadera, se estimaron ambos tipos de relaciones de 
femineidad, por edad individual y por grupos de edad, para el año censal de 1960, buscando comparar la situación de equilibrio de una población como la de 1960 que apenas empezaba a incorporar en sus edades casaderas a aquellas personas nacidas durante la llamada "explosión demográfica", con la de una población como la de 1980, en donde quienes se encuentran entre los 12 y los 35 años de edad nacieron entre 1945 y 1968, esto es, en el periodo en que el ritmo de crecimiento poblacional fue especialmente acelerado. Cabe aclarar que, debido al carácter meramente exploratorio del análisis, éste sólo fue realizado a nivel nacional. La población nacional de 1960 utilizada fue la estimada por Gómez de León y Partida para ese año, también corregida por deficiencias censales, y a la cual se sometió al mismo tratamiento que a la de 1980 , lo que incluyó la desagregación de la población por edad individual, mediante el método del interpolante cúbico de trazador.

$\mathrm{Al}$ analizar la parte $\mathrm{A}$ del cuadro 3 y la gráfica correspondiente (gráfica 9), observamos que a pesar de ciertas diferencias en la forma en que se dio el cambio en el nivel de la relación de femineidad entre ambos años, 1960 y 1980, es indudable que el mayor desequilibrio en la población casadera mexicana de 1980 se encuentra relacionado con el ritmo tan acelerado en que la población creció a partir de 1940, en la medida en que provocó que las poblaciones femeninas que nacieron tres años después que las masculinas con las que se les asoció fuesen cada vez más numerosas; de hecho. al comparar ambas relaciones de femineidad, en el nivel de la $R F(i)$ de 1980 se observan fuertes decrementos a partir de los 19 años, esto es, en las generaciones que nacieron antes de 1961, periodo de crecimiento poblacional por demás intenso.

Finalmente, al conocer que a pesar de haber existido un gran desequilibrio entre los sexos en la población casadera del país de 1980 y la proporción de célibes a los 50 años permaneció en general relativamente baja a nivel nacional y en todas las entidades (Quilodrán, 1987b y 1989), cabe reflexionar un poco sobre cuáles podrían haber sido las respuestas "implementadas" por la sociedad en general y por la población casadera en especial al fuerte desequilibrio entre los sexos estimado en esta investigación.

Quizá las posibles respuestas podrían haberse dirigido en dos direcciones no excluyentes entre sí: la primera, retrasando la edad a la primera unión; la segunda, modificando los patrones socioculturales en cuanto a la edad de la pareja considerada como conveniente. En otras palabras, esperando un poco más para unirse en la búsqueda de una pareja de edad (y características) adecuada(s) y/o reduciendo la diferencia de años entre la edad del hombre y la de la mujer al unirse. 
CUADRO 3

México: relaciones de femineidad por edad y por grupos de edad

\begin{tabular}{|c|c|c|c|c|c|}
\hline $\begin{array}{l}\text { A) Niv } \\
\text { B) Nive }\end{array}$ & $\begin{array}{l}\text { mporta } \\
\text { mporta }\end{array}$ & $\begin{array}{l}\text { en } 196 \\
\text { según }\end{array}$ & $\begin{array}{l}1980 \\
\text { encias }\end{array}$ & $1 y$ & \\
\hline & & & & & \\
\hline & 1960 & & & & \\
\hline Edad & $R F(3)$ & $R F(3)$ & $R F(2)$ & $R F(1)$ & $R F(0)$ \\
\hline 12 & 92.36 & 91.19 & 95.48 & 99.42 & 103.20 \\
\hline 13 & 92.18 & 90.82 & 95.88 & 100.39 & 104.54 \\
\hline 14 & 91.81 & 90.43 & 96.61 & 102.00 & 106.79 \\
\hline 15 & 90.81 & 89.69 & 97.42 & 104.07 & 109.87 \\
\hline 16 & 89.06 & $\mathbf{8 8 . 4 7}$ & 97.98 & 106.42 & $113: 70$ \\
\hline 17 & 86.98 & 86.95 & 98.23 & 108.79 & 118.16 \\
\hline 18 & 85.17 & 85.39 & 98.42 & 111.19 & 123.14 \\
\hline 19 & 84.32 & 84.04 & 98.77 & 113.83 & 128.60 \\
\hline 20 & 85.29 & 83.12 & 99.40 & 116.82 & 134.64 \\
\hline 21 & 88.80 & 82.72 & 100.50 & 120.18 & 141.24 \\
\hline 22 & 94.68 & 82.49 & 101.88 & 123.78 & 148.01 \\
\hline 23 & 101.28 & 81.71 & 102.49 & 126.58 & 153.78 \\
\hline 24 & 106.03 & 79.92 & 101.36 & 127.14 & 157.02 \\
\hline 25 & 107.24 & 77.70 & 98.51 & 124.94 & 156.72 \\
\hline 26 & 104.44 & 75.76 & 94.75 & 120.13 & 152.36 \\
\hline 27 & 99.15 & 74.55 & 91.14 & 113.98 & 144.52 \\
\hline 28 & 94.16 & 74.52 & 88.55 & 108.24 & 135.37 \\
\hline 29 & 90.92 & 75.56 & 87.42 & 103.88 & 126.99 \\
\hline 30 & 89.05 & 76.57 & 87.32 & 101.04 & 120.06 \\
\hline 31 & 88.15 & 76.76 & 87.11 & 99.34 & 114.95 \\
\hline 32 & 87.84 & 76.36 & 86.16 & 97.77 & 111.51 \\
\hline 33 & 87.54 & 75.87 & 85.08 & 96.01 & 108.95 \\
\hline 34 & 86.74 & 75.63 & 84.26 & 94.49 & 106.62 \\
\hline 35 & 85.14 & 75.50 & 83.65 & 93.20 & 104.51 \\
\hline 36 & 82.75 & 75.40 & 83.10 & 92.06 & 102.57 \\
\hline 37 & 79.90 & 75.30 & 82.50 & 90.92 & 100.73 \\
\hline 38 & 77.03 & 75.18 & 81.86 & 89.69 & 98.84 \\
\hline 39 & 74.42 & 75.00 & 81.18 & 88.39 & 96.84 \\
\hline 40 & 72.20 & 74.72 & 80.44 & 87.06 & 94.80 \\
\hline 41 & 70.44 & 74.33 & 79.64 & 85.74 & 92.80 \\
\hline 42 & 69.19 & 73.91 & 78.83 & 84.45 & 90.92 \\
\hline 43 & 68.48 & 73.51 & 78.09 & 83.29 & 89.24 \\
\hline 44 & 68.28 & 73.12 & 77.44 & 82.27 & 87.75 \\
\hline 45 & 68.43 & 72.60 & 76.76 & 81.30 & 86.37 \\
\hline 46 & 68.68 & 71.85 & 75.90 & 80.25 & 85.00 \\
\hline 47 & 68.66 & 70.81 & 74.76 & 78.97 & 83.49 \\
\hline 48 & 67.92 & 69.41 & 73.27 & 77.35 & 81.71 \\
\hline 49 & 66.30 & 67.67 & 71.46 & 75.44 & 79.65 \\
\hline $12-49$ & 89.93 & 85.96 & 96.49 & 107.45 & 118.83 \\
\hline $17-28$ & 90.35 & 83.05 & 98.86 & 116.24 & 134.83 \\
\hline $17-26$ & 89.97 & 83.51 & 99.34 & 116.50 & 134.53 \\
\hline $18-25$ & 90.11 & 83.02 & 99.82 & 118.21 & 137.69 \\
\hline
\end{tabular}

Fuente: véase cuadro 1. 
GRÁFICA 9

República mexicana: perfil de $R F(I), 1960$ y 1980, población soltera estimada

Hom. por 100 muj.

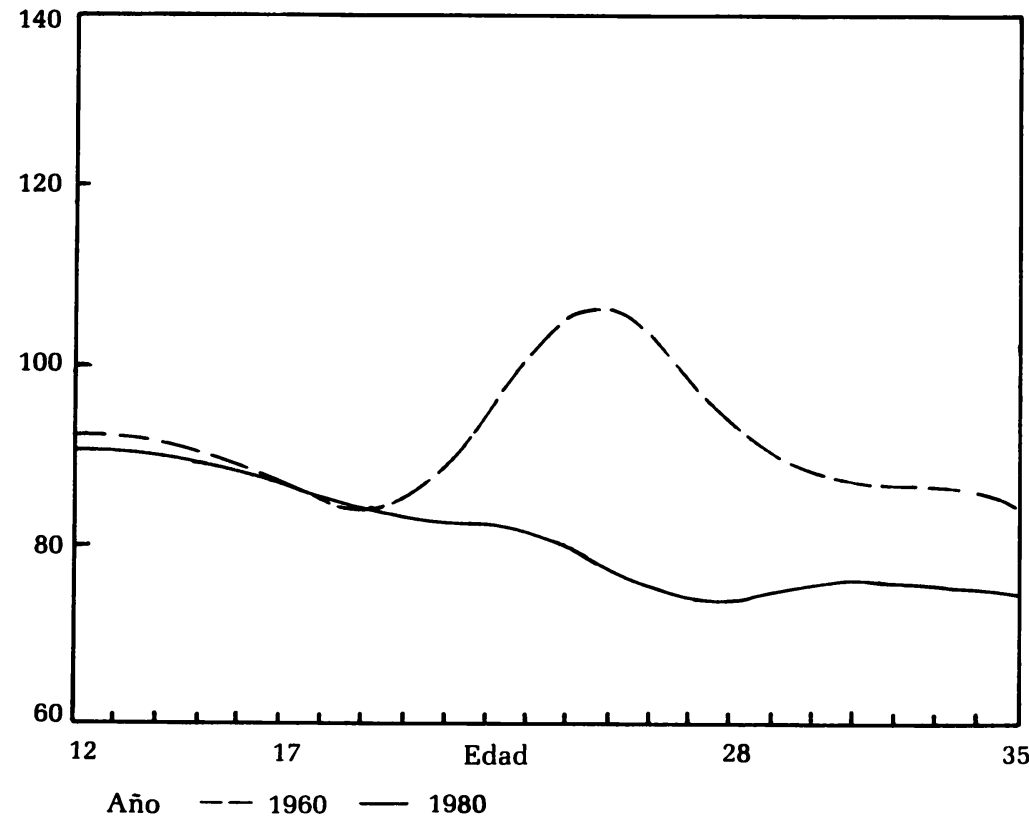

Fuente: cuadro 3.

Debido a que en la presente investigación uno de los aspectos al que se le dio mayor peso fue a la diferencia de edades entre los posibles cónyuges, suponiendo ésta como de tres años entre el hombre y la mujer al momento de unirse, siendo el hombre mayor, examinemos cuál sería la magnitud del desequilibrio, en caso de existir, en el caso de que esta diferencia de edades se redujera. Para evaluar las consecuencias de este tipo de respuesta ante el desequilibrio, se estimaron las relaciones de femineidad por edad individual que suponen diferencias de dos, uno y cero años (este último equivaldría al índice de masculinidad) entre los efectivos solteros en edad casadera de ambos sexos, mismas que se muestran, paralelas a las relaciones ya estimadas (que suponían tres años de diferencia) en la parte $B$ del cuadro 3 y en la gráfica 10.

Como se puede apreciar, los desequilibrios siguen existiendo, pero los déficits de hombres que los originan son de menor magni- 
tud que los encontrados a través de suponer tres años de diferencia entre posibles cónyuges, y se van reduciendo a medida que disminuye la diferencia de edades entre el hombre y la mujer hasta transformarse en desequilibrios provocados por déficits que ahora son de mujeres, como lo demuestra el nivel y comportamiento de la $R F(1)$ y la $R F(0)$.

En cuanto a la edad media a la primera unión masculina y femenina, ésta, a nivel nacional, no ha sufrido cambios importantes, ya que ha variado, respectivamente, de 24.5 y 21.1 en 1979 a 24.1 y 21.6 en 1980 (Quilodrán, J., 1989).

Así, es posible pensar que la sociedad mexicana, al enfrentarse a un fenómeno demográfico de la índole del que aquí evidenciamos, el desequilibrio entre los sexos en su población casadera, ha empleado mecanismos que no han ido en el sentido de retrasar sustancialmente la edad a la primera unión, sino en el de una

GRÁFICA 10

República mexicana: RF(3), (2), (1) y (0), población soltera estimada, 1980

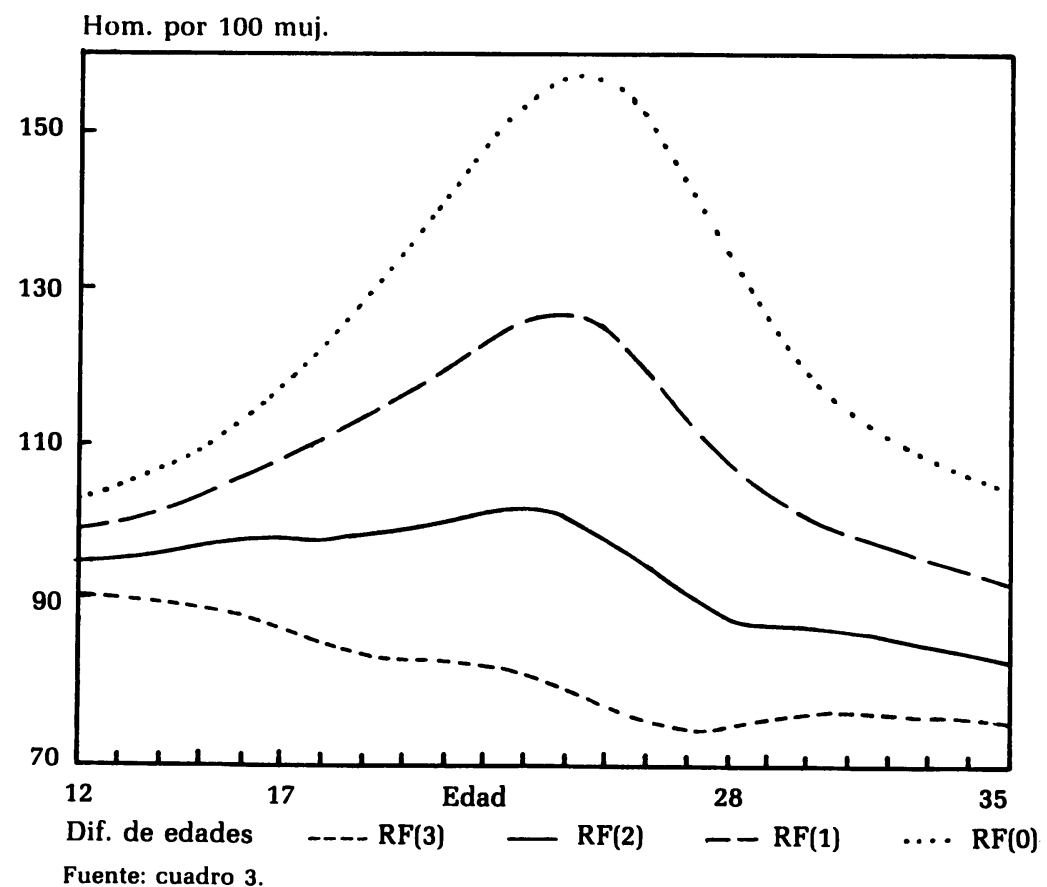


transformación más profunda en las costumbres socioculturales que regulan la dinámica de uniones, específicamente en lo que se refiere a la diferencia de edades entre los posibles cónyuges.

\section{Bibliografía}

Akers, D.S. (1967). "On Measuring the Marriage Squeeze", en Demography, vol. 4, núm. 2, pp. 907-923.

Burden, R.L. y Faires, J.D. (1985). "Interpolante cúbico de trazador", en Análisis Numérico, México, Grupo Editorial Iberoamérica.

Coale, Ansley J. (1971). "Age Patterns of Marriage", en Population Studies, vol. XXV, núm. 2, pp. 193-214.

(1972). Growth and Structure of Human Populations, Princeton, Princeton University Press.

Conapo-INEGi (1985). "Proyecciones de la población de México y de las entidades federativas: 1980-2010", México, SPP.

Dixon, R.B. (1971). "Explaining Cross-Cultural Variations in Age at Marriage and Proportions Never Marrying", en Population Studies, vol. 25, núm. 2, pp. 215-233.

(1978). "Late Marriage and Non-Marriage as Demographic Responses: Are They Similar?", en Population Studies, vol. 32, núm. 3, pp. 453-458.

Girard, A. (1964). "Le choix du conjoint", París, INED.

Glick, P.C., D.M. Heer y J.C. Beresford (1963). "Family Formation and Family Composition: Trends and Prospects", en Marvin B. Sussman, (ed.), Soucebook in Marriage and the Family, Nueva York, Hougthon Mifflin, p. 38.

Goldberg, D. (1966). "Fertility and Fertility Differentials: Some Observations on Recent Changes in the United States", en Mindel C. Sheps y Jeanne C. Ridley (eds.), Public Health and Population Change, Pittsburgh, University of Pittsburgh Press.

Goldman, N., Ch.F. Westoff y Ch. Hammerslough (1984). "Demography of the Marriage Market in the United States", en Population Index, vol. 50, núm. 1, pp. 5-25.

Gómez de León, J. y V. Partida (1986). "Completeness of Ennumeration of the 1980 Census of Mexico: An Appraisal Based on New Estimates of Intercensal Net Migration, 1960-1980", ponencia presentada en la Second Annual Research Conference, 23-26 de marzo, en Proceedings, Washington, U.S. Department of Commerce, Bureau of the Census, pp. 627-649. Versión en español en Memoria del Taller Nacional de Evaluación del Censo General de Población y Vivienda. 1980, vol. 2, abril de 1986, Querétaro, México, INEGI, pp. 1511-1552.

Henry, L. (1966). "Perturbations de la nuptialité résultant de la guerre 1914-1918", en Population, vol. 21, núm. 2, pp. 273-332. 
(1968), "Problèmes de la nuptialité. Considération de méthode", en Population, vol. 23, núm. 5, pp. 835-844.

(1969a). "Schémas de nuptialité: déséquilibre des sexes et célibat", en Population, vol. 24, núm. 3, pp. 457-485.

(1969b). "Schémas de nuptialité: déséquilibre de sexes et age au mariage", en Population, vol. 24, núm. 6, pp. 1067-1122.

(1972). "Nuptiality", en Theoretical Population Biology, vol. 3, núm. 2, pp. 135-152.

(1975). "Schéma d'évolution des mariages après de grandes variations des naissances", en Population, vol. 30, núm. 2, pp. 759-779.

Hirschman, C. y Matras, J. (1971). "A New Look at the Marriage Market and Nuptiality Rates, 1915-1958”, en Demography, vol. 8, núm. 4, pp. 549-569.

Kotler, P. (1984). Marketing Management: Analysis, Planning, and Control, 5a. ed., Englewood Cliffs, N.J., Prentice-Hall.

Levy, M.L. (1980). “L'Equilibre des sexes”, en Population et Société, núm. 132.

Quilodrán, J. (1974). "Evolución de la nupcialidad en México, 19001970", en Demografía y Economía, vol. viII, núm. 1, México, El Colegio de México.

(1979). "La nupcialidad en las áreas rurales de México", en Demografía y Economía, vol. xiII, núm. 3, México, El Colegio de México. (1980). "Tablas de nupcialidad para México", en Demografía y Economía, vol. xIV, núm. 1, México, El Colegio de México.

(1986). "El estado civil en los censos mexicanos", en Memoria del Taller Nacional de Evaluación del Censo General de Población y Vivienda, 1980, Querétaro, México, INEGI, pp. 2027-2061.

(1987a). "Particularidades de la nupcialidad fronteriza", ponencia presentada al Simposio Binacional sobre Población en la Frontera Norte, Tijuana, B.C., (versión revisada).

(1987b). "Diferencias de nupcialidad por regiones y tamaños de localidad", ponencia presentada en el seminario Demografía y Urbanización en México, El Colegio de México.

(1989). "Algunas implicaciones demográficas y sociales de la dinámica de las uniones", en M.P. de Nliveira, Lehaller y Sales (comps.), Grupos domésticos y reproducción cotidiana, México, UNAM-El Colegio de México, pp. 81-103.

Schoen, R. (1983). "Measuring the Tightness of a Marriage Squeeze", en Demography, vol. 20, núm. 1, pp. 61-78.

VIII Censo General de Población (1960), "Resumen general”, México, Secretaría de Industria y Comercio, 1962.

$x$ Censo General de Población y Vivienda (1980), México, Instituto Nacional de Estadística, Geografía e Informática. 